\title{
SPECTROPHOTOPOLARIMETRY AS A METHOD FOR DETERMINING THE TIME DYNAMICS OF CHANGES IN THE MORPHOLOGICAL STRUCTURE OF MUSCLE TISSUE
}

\author{
Olexandr Harazdiuk ${ }^{1}$, Nataliia Kozan ${ }^{2}$, Viktor Kryvetskyi ${ }^{3}$, Oleksandr Dunaiev $^{4}$
}

\begin{abstract}
:
Introduction: The article presents the current state of issues regarding the diagnosis of pathological conditions for forensic medical experts, in particular the study of normal muscle tissue and in the presence of hemorrhages. Particular attention is paid to biophysical research methods with evidence-based accuracy, objectivity, reproducibility, and rapid results.

Objectives: The purpose of the research was to study the possibilities of using spectrophotopolyarimetric methods to analyze and determine the relationship of morphological structure of biological tissues with the temporal dynamics of changes in their optical parameters, to establish the possibility of differentiating necrotic changes and signs of damage by applying Mueller matrices of human muscle tissue samples.

Results: During the study, we found a number of features and patterns of change in the properties of the laser beam as a result of passing through biological tissue. Polarization-correlation methods provide new, objective information about the dynamics of change in laser polarimetric imaging of morphological structure of biological tissues. By analyzing the statistical distributions of the ellipticity of polarization of laser images of normal human muscle tissue and in the presence of hemorrhages, the possibility of identifying the relationship between the development of statistically significant changes with increasing time of death and the possibility of differentiating them are considered.

Conclusion: Based on these results, we can conclude that employing laser polarization methods will allow us to open new doors in the study of the biological tissues of the human body. The results showed the effectiveness of the studied methodology and the prospect of further research in this direction.
\end{abstract}

UDC Classification: 616-091, DOI: https://doi.org/10.12955/pmp.v2.169

Keywords: differentiation, muscle tissue, polarization, laser polarimetry, spectrophotopolyarimetry, forensic medicine.

\section{Introduction}

To date, in studying the morphological features of biological tissues of the human body, researchers are faced with a number of issues, particularly in forensic medicine, that cannot be solved without developing new approaches to the diagnosis of pathological conditions. Recent advances in science, technology, and new diagnostic methods in medicine allow us to find new approaches to solving urgent practical problems. (Carew et al., 2019; Aalders, et al., 2017)

Modern digital techniques for evaluating biological tissues, such as laser polarization techniques, have proven themselves well. (Bachinskyi et al., 2020; Garazdyuk et al., 2016; Protsiuk et al., 2020) According to this methodology, the whole spectrum of biological tissues can be represented as a set of fibrillar protein structures that form their own unique structural and functional organization. An important feature of these proteins is their strict order, which gives them the properties of liquid crystals. Given these facts, biological tissues can be investigated using laser polarimetry methods. (Li, et al., 2017; Ushenko, et al., 2019). These methods provide the most complete information on the polycrystalline structure of biological tissues and fluids of the human body and allow to study of the dynamics of changes in different pathological conditions. (Ushenko, et al., 2017; Wang, et al., 2016). A distinctive feature of biophysical research methods is the high sensitivity and the ability to accurately, objectively record the results.

\section{Purpose}

The purpose of the research was to study the possibilities of using spectrophotopolyarimetric methods to analyze and determine the relationship of the morphological structure of biological tissues with the temporal dynamics of changes in their optical parameters, to establish the possibility of differentiating

\footnotetext{
${ }^{1}$ Bukovinian State Medical University, Internal Medicine and Infectious Diseases Department, Chernivtsi, Ukraine, olexandr.harazdiuk@gmail.com

${ }^{2}$ Ivano-Frankivsk National Medical University, Forensic Medicine and Medical Law Department, IvanoFrankivsk, Ukraine

${ }^{3}$ Bukovinian State Medical University, Human Anatomy named after M.G. Turkevich Department, Chernivtsi, Ukraine

${ }^{4}$ Kharkiv National Medical University, Forensic Medicine, Medical Law named after M.S. Bocarius Department, Kharkiv, Ukraine
} 
necrotic changes and signs of damage by applying Mueller matrices of human muscle tissue (MT) samples.

\section{Materials and Methods}

The study was based on a two-component model for describing biological tissue structure: isotropic and anisotropic or crystalline. (Ushenko et al., 2016). The state of polarization of light changes when radiation passes through a sample of biological tissue and when reflected from its surface. The application of laser polarimetry methods in forensic medicine is based on the analysis of these parameters. These techniques provide an analysis of a wide range of parameters, which allows to obtain important information about biological tissues' morphological structure and properties. (Ushenko et al., 2015; Vanchulyak et al., 2019).

The object of the study was histological sections of human skeletal MT fibers with hemorrhages in these areas and without them (control group), selected from 96 corpses of both sexes. Native histological sections up to $60 \mathrm{mkm}$ thick were obtained from the extracted samples of human MT using a freezing microtome. The studies were carried out using the standard scheme of the spectropolarimeter (Figure 1).

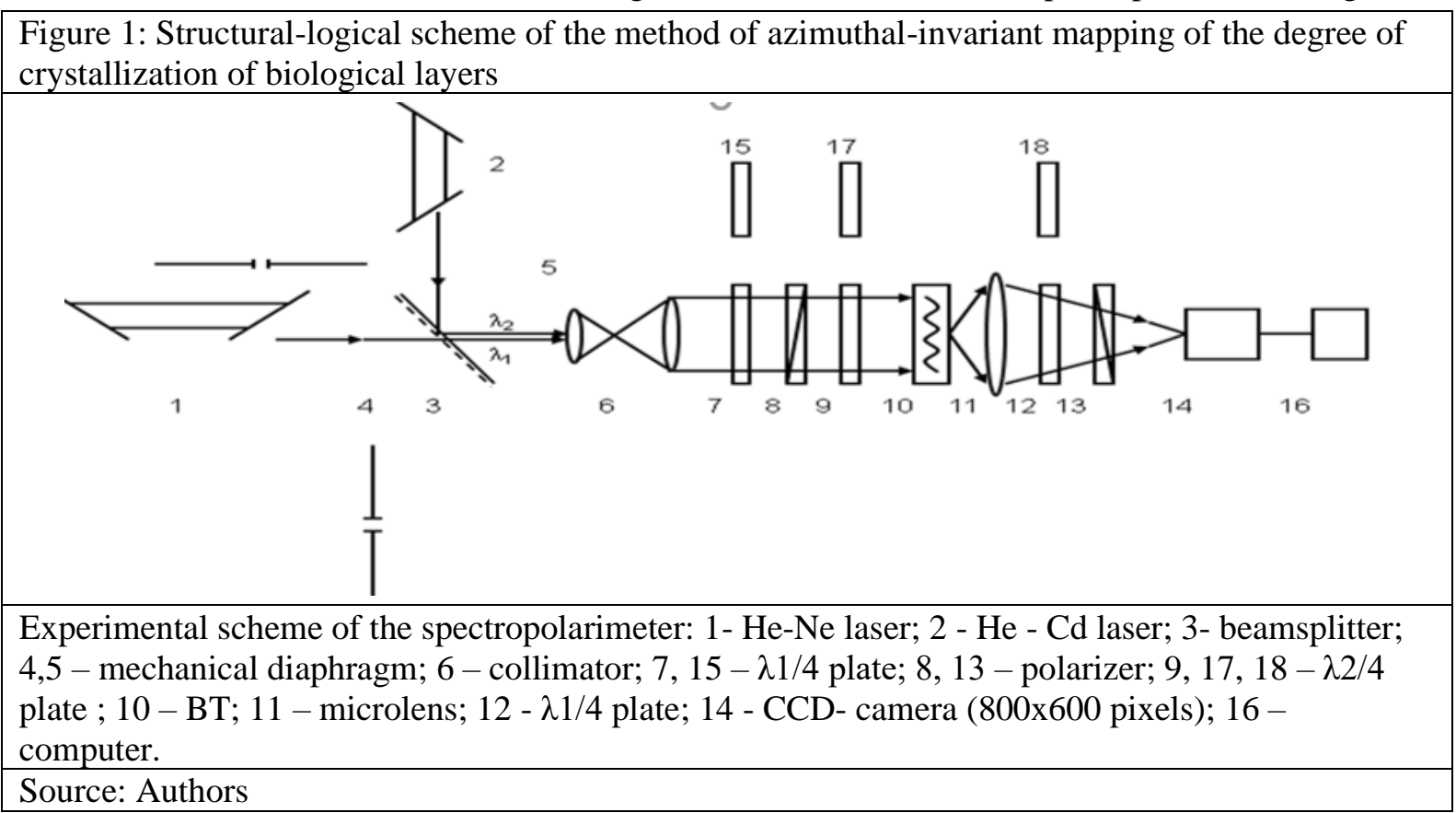

Human muscle tissue samples were illuminated with parallel beams He-Ne laser $(\lambda I=0.633 \mathrm{~mm}, \mathrm{~W}=$ $10.0 \mathrm{mBt})$ and He-Cd laser $(\lambda 2=0.414 \mathrm{~mm}, \mathrm{~W}=10.0 \mathrm{mBt})$. The laser beams were sequentially directed to the beam splitter, which made the orientation in the direction of the collimator, which formed a parallel beam of rays $(\varnothing=102 \mathrm{~mm})$. The optical path was blocked with mechanical diaphragms in order to achieve alternate illumination with lazars. Polarizing illuminator (for each wavelength consisted of plates $\lambda 1 / 4, \lambda 2 / 4$, and a polarizer) formed linearly polarized laser beams. Polarized images of human MT samples using microlens were projected into the light-sensitive plane of a CCD camera. The methodology of this research method is detailed in the works of Ushenko A.G. et al.

Statistical moments of 1-4 orders of magnitude were used as the main analytical tool for assessing the distribution of random variables that characterize the images and structure of human MT. Calculations were carried out using the following algorithm (Ushenko, et al., 2017; Wang, et al., 2016):

$$
\begin{aligned}
& Z_{1}^{\delta}=\frac{1}{N} \sum_{i=1}^{N}|J| \\
& Z_{2}^{\delta}=\sqrt{\frac{1}{N} \sum_{i=1}^{N} J^{2}} \\
& Z_{3}^{\delta}=\frac{1}{\left(Z_{2}^{\delta}\right)^{3}} \frac{1}{N} \sum_{i=1}^{N} J^{3}
\end{aligned}
$$




$$
Z_{4}^{\delta}=\frac{1}{\left(Z_{2}^{\delta}\right)^{2}} \frac{1}{N} \sum_{i=1}^{N} J^{4}
$$

\section{Results}

In control and experimental groups, the polarization structure of laser images at different time intervals after death was studied. A series of polarized laser images of histological sections of MT from the control and experimental groups indicates the presence of a structured grid of optically anisotropic myosin fibrils (Figure 2, 3).

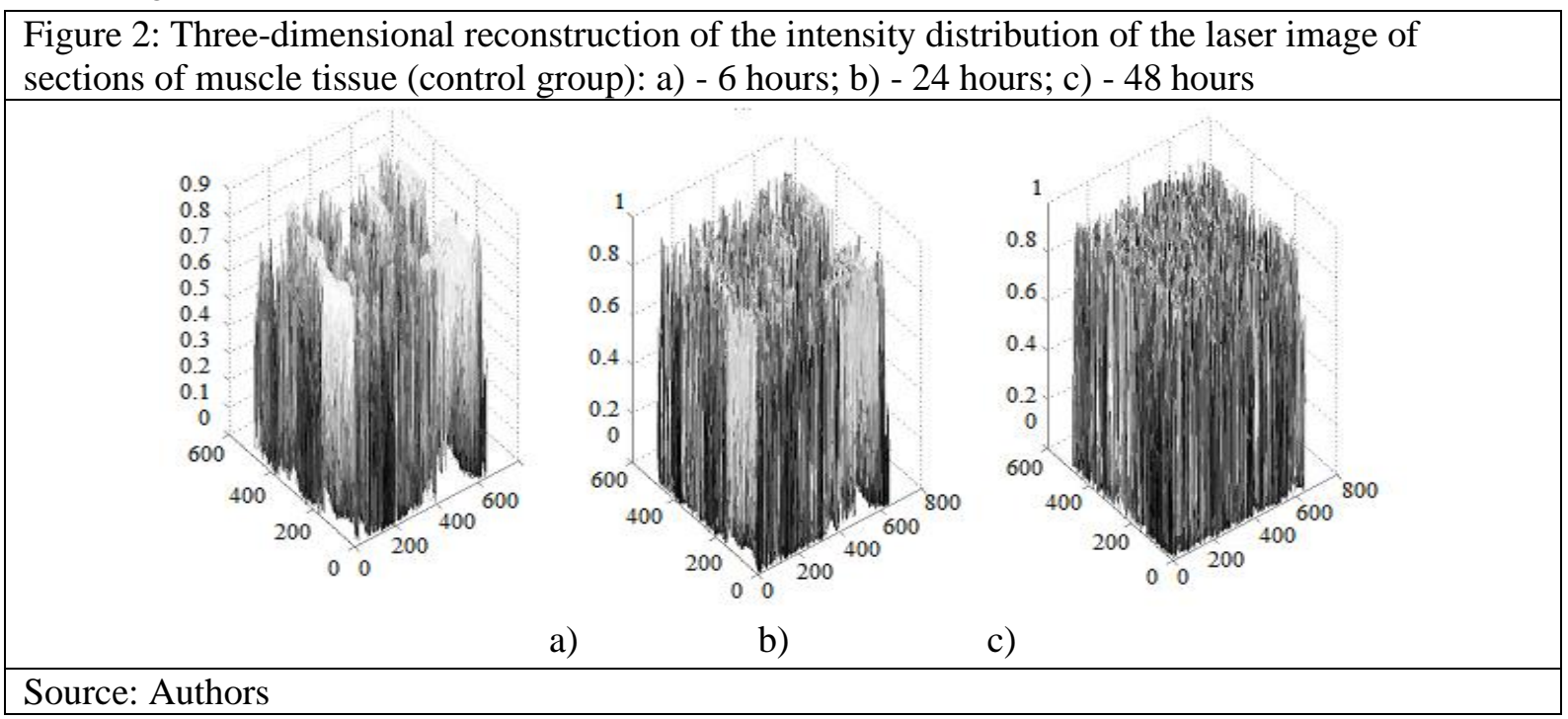

Thus, the application of the method of polarization filtering of laser images of human MT opens the possibility of direct study of the structure of their extracellular matrices. The information obtained can objectively assess the processes of temporal dynamics of structural changes in human tissues and identify various pathological conditions. The comparative analysis shows that the value of the extremes of local values of intensity in the area of hemorrhage is much lower than the value in the image of intact areas. This feature can be explained by the more intense absorption of radiation in the area of hemorrhage. Thus, the intensity of the image in such places is less than in areas without hemorrhage.

In order to quantify the identified differences in the statistical and coordinate structure of the distributions of the degree of depolarization, the statistical moments of the 1st - 4th orders were calculated. Table 1 shows the statistical parameters of the distributions of the values of depolarization of laser images of MT, in the presence of hemorrhages and without them, according to the period after death.

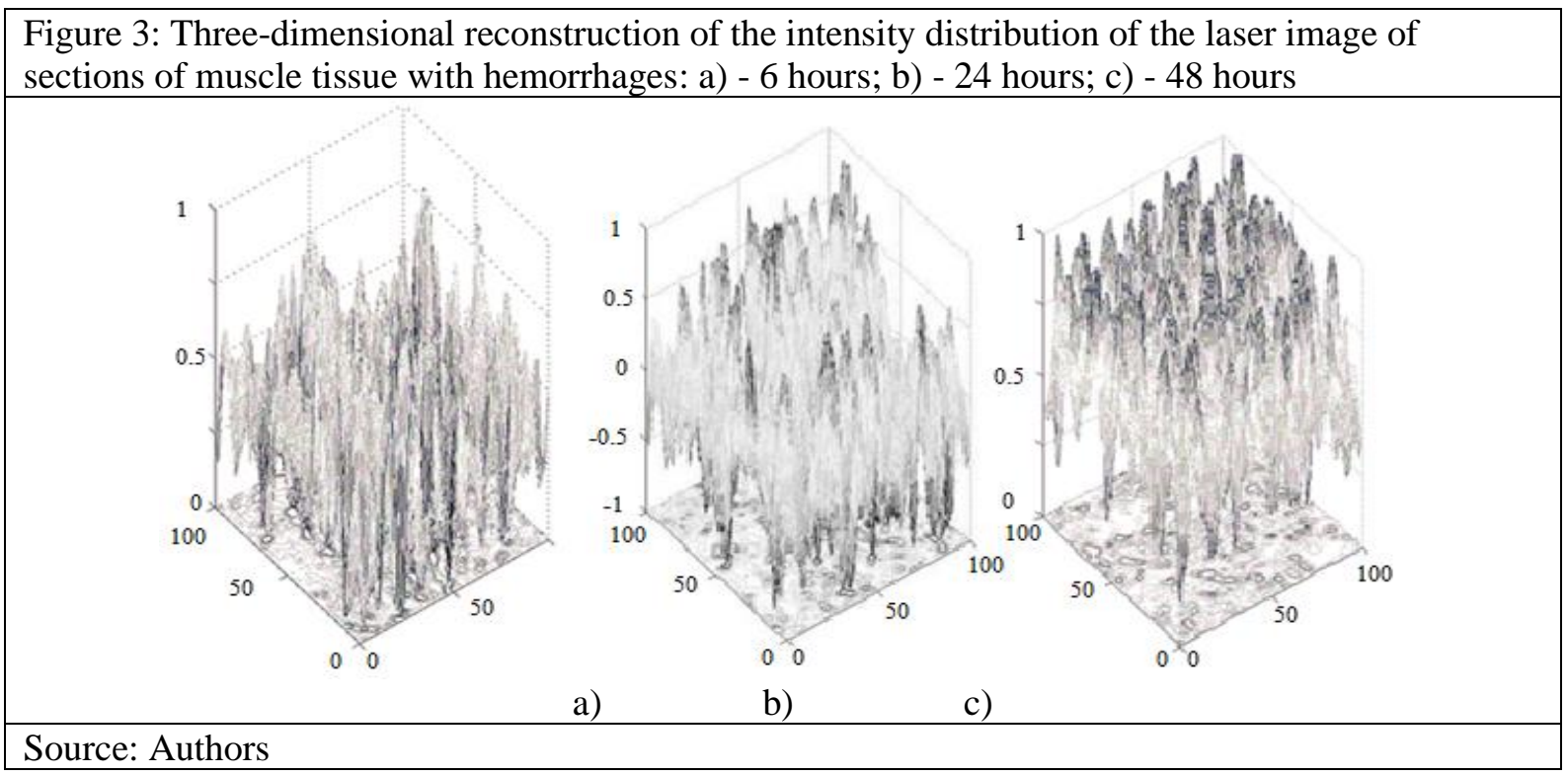


The obtained data indicate a high level of sensitivity of this research method to the detection of specific postmortem changes in the protein structure of MT, which is manifested in the change in the anisotropy of the polarization structure of MT images. The probabilities of random values of statistical moments of the 1-2nd order with increasing observation time after death have a pronounced tendency to redistribution to the minimum values, while the values of asymmetry and excess increase (Table 1).

\begin{tabular}{|c|c|c|c|c|c|}
\hline \multirow{2}{*}{\multicolumn{6}{|c|}{$\begin{array}{l}\text { Table 1: Central statistical moments of the 1st - 4th orders characterize the c } \\
\text { of the values of polarization parameters of the MT images from the control } \\
\text { groups. }\end{array}$}} \\
\hline & & & & & \\
\hline $\begin{array}{l}\text { statistical } \\
\text { moments }\end{array}$ & 1 hour & 12 hours & 24 hours & 36 hours & 48 hours \\
\hline$Z_{l}$ & $\begin{array}{c}2.261 \pm \\
0.037 \\
\end{array}$ & $\begin{array}{c}2.185 \pm \\
0.032 \\
\end{array}$ & $\begin{array}{c}1.824 \pm \\
0.027 \\
\end{array}$ & $\begin{array}{c}1.671 \pm \\
0.021 \\
\end{array}$ & $\begin{array}{c}1.281 \pm \\
0.012 \\
\end{array}$ \\
\hline$\rho_{1}$ & $(\rho \leq 0.05)$ & $(\rho \leq 0.05)$ & $(\rho \leq 0.05)$ & $(\rho \leq 0.05)$ & $(\rho \leq 0.05)$ \\
\hline$Z_{2}$ & $\begin{array}{l}0.836 \pm \\
0.0321\end{array}$ & $\begin{array}{c}0.723 \pm \\
0.032\end{array}$ & $\begin{array}{c}0.687 \pm \\
0.020\end{array}$ & $\begin{array}{c}0.562 \pm \\
0.029\end{array}$ & $\begin{array}{c}0.483 \pm \\
0.023\end{array}$ \\
\hline$\rho_{2}$ & $(\rho \leq 0.05)$ & $(\rho \leq 0.05)$ & $(\rho \leq 0.05)$ & $(\rho \leq 0.05)$ & $(\rho \leq 0.05)$ \\
\hline$Z_{3}$ & $\begin{array}{c}1.140 \pm \\
0.027\end{array}$ & $\begin{array}{c}1.614 \pm \\
0.022 \\
\end{array}$ & $\begin{array}{c}1.804 \pm \\
0.021 \\
\end{array}$ & $\begin{array}{c}2.350 \pm \\
0.01 \\
\end{array}$ & $\begin{array}{c}2.980 \pm \\
0.020 \\
\end{array}$ \\
\hline$\rho_{3}$ & $(\rho \leq 0.05)$ & $(\rho \leq 0.05)$ & $(\rho \leq 0.05)$ & $(\rho \leq 0.05)$ & $(\rho \leq 0.05)$ \\
\hline$Z_{4}$ & $\begin{array}{c}1.245 \pm \\
0.027\end{array}$ & $\begin{array}{c}1.764 \pm \\
0.033\end{array}$ & $\begin{array}{c}1.985 \pm \\
0.041\end{array}$ & $\begin{array}{c}2.249 \pm \\
0.042\end{array}$ & $\begin{array}{c}2.989 \pm \\
0.040\end{array}$ \\
\hline$\rho_{4}$ & $(\rho \leq 0.05)$ & $(\rho \leq 0.05)$ & $(\rho \leq 0.05)$ & $(\rho \leq 0.05)$ & $(\rho \leq 0.05)$ \\
\hline \multicolumn{6}{|c|}{ Histological sections of the MT with hemorrhage $(n=5 I)$} \\
\hline$Z_{1}$ & $\begin{array}{c}1.084 \pm \\
0.031 \\
\end{array}$ & $\begin{array}{c}1.324 \pm \\
0.028 \\
\end{array}$ & $\begin{array}{c}1.534 \pm \\
0.027 \\
\end{array}$ & $\begin{array}{c}1.860 \pm \\
0.021 \\
\end{array}$ & $\begin{array}{c}1.981 \pm \\
0.020 \\
\end{array}$ \\
\hline$\rho_{1}$ & $(\rho \leq 0.05)$ & $(\rho \leq 0.05)$ & $(\rho \leq 0.05)$ & $(\rho \leq 0.05)$ & $(\rho \leq 0.05)$ \\
\hline$Z_{2}$ & $\begin{array}{l}0.713 \pm \\
0.0141 \\
\end{array}$ & $\begin{array}{c}0.623 \pm \\
0.012\end{array}$ & $\begin{array}{c}0.567 \pm \\
0.011 \\
\end{array}$ & $\begin{array}{c}0.388 \pm \\
0.009\end{array}$ & $\begin{array}{c}0.272 \pm \\
0.013 \\
\end{array}$ \\
\hline$\rho_{2}$ & $(\rho \leq 0.05)$ & $(\rho \leq 0.05)$ & $(\rho \leq 0.05)$ & $(\rho \leq 0.05)$ & $(\rho \leq 0.05)$ \\
\hline$Z_{3}$ & $\begin{array}{c}1.081 \pm \\
0.027\end{array}$ & $\begin{array}{c}1.360 \pm \\
0.023\end{array}$ & $\begin{array}{c}1.604 \pm \\
0.022 \\
\end{array}$ & $\begin{array}{c}1.981 \pm \\
0.015\end{array}$ & $\begin{array}{c}2.021 \pm \\
0.011\end{array}$ \\
\hline$\rho_{3}$ & $(\rho \leq 0.05)$ & $(\rho \leq 0.05)$ & $(\rho \leq 0.05)$ & $(\rho \leq 0.05)$ & $(\rho \leq 0.05)$ \\
\hline$Z_{4}$ & $\begin{array}{c}1.205 \pm \\
0.037 \\
\end{array}$ & $\begin{array}{c}1.384 \pm \\
0.034 \\
\end{array}$ & $\begin{array}{c}1.584 \pm \\
0.032 \\
\end{array}$ & $\begin{array}{c}1.873 \pm \\
0.022 \\
\end{array}$ & $\begin{array}{c}2.328 \pm \\
0.025 \\
\end{array}$ \\
\hline$\rho_{4}$ & $(\rho \leq 0.05)$ & $(\rho \leq 0.05)$ & $(\rho \leq 0.05)$ & $(\rho \leq 0.05)$ & $(\rho \leq 0.05)$ \\
\hline
\end{tabular}

The obtained data show that the whole set of statistical moments of the coordinate distribution of the values of the laser image of the histological section of the skeletal muscle tissue has reliable and nonzero values. The obtained statistical information about the properties of the histological section of human MT can be used to characterize its properties objectively.

The decrease in the values of statistical moments of the 1-2nd order and the increase in the values of statistical moments of higher orders with increasing time after death can be associated with a decrease in the level of optical anisotropy of MT architecture.

The study revealed a fairly wide range of dynamics of changes in statistical moments of the 1st-4th orders from 1 to 48 hours.

A comparative analysis of the average set of central statistical moments of 1 - 4th orders was performed (Table 2).

The analysis revealed the diagnostic efficiency (statistical reliability $\rho<0.05$ ) of the spectrophotopolarimetric method in the differentiation of MT samples of control and experimental groups.

The obtained results allow us to state that the proposed method is effective in solving a number of forensic issues, in particular the establishment of the presence of damage in the study areas and the time of their occurrence. These issues are extremely important, as they are of crucial medical and legal importance in investigating crimes to establish responsibility for their commission. According to world 
Table 2: Statistically averaged values of statistical moments of the 1st - 4th orders, which characterize the coordinate distributions of the values of MT image polarization parameters from the control and experimental groups in 24 hours after death

\begin{tabular}{|c|c|c|}
\hline Sample & \multicolumn{2}{|c|}{ histological sections of MT } \\
\hline statistical moments & group $1(\mathrm{n}=45)$ & group $2(\mathrm{n}=56)$ \\
\hline$Z_{1}$ & $1.824 \pm 0.027$ & $1.534 \pm 0.027$ \\
\hline$\rho_{1} ; \rho_{2}$ & $\rho_{1}<0.05$ & $\rho_{2}<0.05$ \\
\hline$\rho_{1 ; 2}$ & $0.687 \pm 0.020$ & $\rho_{1} ; 2<0.05$ \\
\hline$Z_{2}$ & $\rho_{1}<0.05$ & $\rho_{2}<0.05$ \\
\hline$\rho_{1} ; \rho_{2}$ & $1.804 \pm 0.021$ & $\rho_{1} ; 2<0.05$ \\
\hline$\rho_{1} ; 2$ & $\rho_{1}<0.05$ & $\rho_{2}<0.05$ \\
\hline$Z_{3}$ & $1.985 \pm 0.041$ & $\rho_{1} ; 2<0.05$ \\
\hline$\rho_{1} ; \rho_{2}$ & $\rho_{1}<0.05$ & $\rho_{2}<0.05$ \\
\hline$\rho_{1} ; 2$ & \multicolumn{2}{|c|}{$\rho_{1} ; 2<0.05$} \\
\hline$Z_{4}$ & $\rho_{1} ; \rho_{2}$ & \multicolumn{2}{|c|}{} \\
\hline$\rho_{1} ; 2$ & & \\
\hline &
\end{tabular}

Source: Authors

literature sources, experts in practice use mostly visual and descriptive methods, and then to clarify the results - histological, histochemical and immunohistochemical methods of research. (Siddiqui et al., 2016; Ibrahim et al., 2019). Siddiqui et al. described the possibility of using a histopathological method to establish a causal relationship between the time of injury and the time of death. In other scientific works, the authors propose an assessment of early molecular changes of miRNAs in damaged areas. (Ibrahim et al., 2019). Similarly, as in our study, the results are based on the detected progressive morphological changes in the areas of damage with increasing interval after death. However, we would like to note that all the above-described techniques, in contrast to laser spectrophotopolarimetry, are quite time-consuming and relatively expensive and depend largely on the researcher's subjective assessment.

\section{Conclusion}

Thus, the topographic and statistical structure of maps of polarized images of normal human MT and with hemorrhages was studied. The interval of dynamics of change of statistical moments of the 1st-4th orders from 1 to 48 hours is established. The possibility of statistically significant differentiation of histological samples of MT with and without hemorrhages has been established, which becomes extremely relevant in the practice of a forensic experts in resolving important issues.

Based on these results, we can conclude that the use of laser polarization methods will allow us to open new doors for the study of biological tissues of the human body. The results showed the effectiveness of the studied methodology and the prospects for further research in this direction, in particular the search for relationships between pathological changes in biological tissues and the polarization parameters of their images and architecture.

\section{References}

Aalders, M. C., Adolphi, N. L., Daly, B., Davis, G. G., De Boer, H. H., Decker, S. J., ... \& Wozniak, K. (2017). Research in forensic radiology and imaging; Identifying the most important issues. Journal of Forensic Radiology and Imaging, 8, 1-8. doi.org/10.1016/j.jofri.2017.01.004

Bachinskyi, V. T., Wanchulyak, O. Y., Ushenko, A. G., Ushenko, Y. A., Dubolazov, A. V., \& Meglinski, I. (2020). Polarization Correlometry of Scattering Biological Tissues and Fluids (p. 1). Springer Singapore.

Carew, R. M., Errickson, D. (2019). Imaging in forensic science: five years on. Journal of Forensic Radiology and Imaging, 16, 24-33. doi.org/10.1016/j.jofri.2019.01.002

He, H., He, C., Chang, J., Lv, D., Wu, J., Duan, C., ... \& Ma, H. (2017). Monitoring microstructural variations of fresh skeletal muscle tissues by Mueller matrix imaging. Journal of biophotonics, 10(5), 664-673.

Ibrahim, S. F., Ali, M. M., Basyouni, H., Rashed, L. A., Amer, E. A., \& Abd El-Kareem, D. (2019). Histological and miRNAs postmortem changes in incisional wound. Egyptian Journal of Forensic Sciences, 9(1), 1-6.

Garazdyuk, M.S., Bachinskyi, V.T., Vanchulyak, O.Y., Ushenko, A.G., Dubolazov, O.V., Gorsky, M.P. (2016). Polarizationphase images of liquor polycrystalline films in determining time of death. Applied Optics, 55(12): B67-B71. doi: 10.1364/AO.55.000B67 
Li, X., Hu, H., Wu, L., \& Liu, T. (2017). Optimization of instrument matrix for Mueller matrix ellipsometry based on partial elements analysis of the Mueller matrix. Optics express, 25(16), 18872-18884.

Protsiuk, V. V., Vasiyk, V. L., Vasilchysin, Y. M., Kvasnyuk, D. I., Ushenko, A. G., Shaplavskiy, M. V., ... \& Tomka, Y. Y. (2020). Differential diagnosis of aseptic and septic loosening of an artificial hip joint endoprosthesis cup using spectralselective laser autofluorescence microscopy. In Fourteenth International Conference on Correlation Optics (Vol. 11369, p. 113691Z). International Society for Optics and Photonics. https://doi.org/10.1117/12.2553990

Siddiqui, M. A. M., Parvathi, K., Khan, M. T., \& Reddy, M. N. (2016). Histopathological study of blunt force injuries in relation to time since death. J Contemp Med Res, 3(9), 2780-2783.

Ushenko, V. A., Sdobnov, A. Yu., Mishalov, W. D., Dubolazov, A. V., Olar, O. V., Bachinskyi, V. T. ... Meglinski I. (2019). Biomedical applications of Jones-matrix tomography to polycrystalline films of biological fluids. Journal of Innovative Optical Health Sciences, 12(6), 1950017. doi: 10.1142/S1793545819500172.

Ushenko, V. A., Prysyazhnyuk, V. P., Dubolazov, O. V., Karachevtsev, A. O., Olar, O. I., Olar, O. V., ... Savich, V. O. (2015). Polarization-correlation microscopy of human liquid polycrystalline films in infertility diagnosis. Proceedings of SPIE, 9599, Applications of Digital Image Processing, XXXVIII, 959922. doi: https://doi.org/10.1117/12.2187448

Ushenko, A. G., Dubolazov, A. V., Ushenko, V. A., Ushenko, Yu. A., Sakhnovskiy, M. Yu., Sidor, M., ... Lakusta, I. I. (2016). Methods and means of Stokes-polarimetry microscopy of optically anisotropic biological layers. Proceedings of SPIE, 10010, Advanced Topics in Optoelectronics, Microelectronics, and Nanotechnologies, VIII, 100100M. doi: https://doi.org/10.1117/12.2242628

Vanchulyak, O., Ushenko, Y., Galochkin, O., Sakhnovskiy, M., Kovalchuk, M., Dovgun, A. ...Bodnar, G. (2019). Azimuthal fractalography of networks of biological crystals. Proceedings of SPIE, 11105, Novel Optical Systems, Methods, and Applications, XXII, 1110517. doi: https://doi.org/10.1117/12.2529337

Wang, Y., He, H., Chang, J., He, C., Liu, S., Li, M., ... \& Ma, H. (2016). Mueller matrix microscope: a quantitative tool to facilitate detections and fibrosis scorings of liver cirrhosis and cancer tissues. Journal of biomedical optics, 21(7), 071112. 